\title{
ELEMENTOS DE AVALIAÇÃO DO "RISCO GRAVIDICO"
}

\section{RSPSP-117}

Ciari JR., C. \& Almeida, P. A. M. de Elementos de avaliação do "risco gravidico". Rev. Saúde públ., S. Paulo, 6: $57-78,1972$.

RESUMo: São estabelecidos alguns conceitos básicos que definem o "risco gravídico" propondo-se uma classificação dos elementos que devem ser considerados no estabelecimento do risco. Com o objetivo de quantificar a avaliaçäo do risco e baseados nos fatores da classificação são atribuídos notas cuja soma determina um valor que mede a intensidade do "risco gravídico". Calcados nestes valores são estudados, retrospectivamente, 62 obitos maternos distribuidos em tabelas onde se associam difenentes fatores. Verifica-se, em conclusão, que um adequado programa de Saúde Materna é necessário não so para atender às gestantes durante o Pré-Natal como também facultar oportuna assistência hospitalar. $A$ analise dos bbitos $e$ os fatores que determinaram $o$ alto risco sugerem elementos para a elaboração de Programas de Saúde Materna.

UNITERMos: Gravidez*; Saúde materna*; Risco gravidico*.

\section{INTRODUCGA}

Um dos fatores que tem decisiva influência na elaboração de programa de Saúde Materna e sua posterior avaliação é a determinação do chamado "risco gravídico"** porque, através da análise de sua

\section{Cyro CIARI JÚNIOR *}

Pedro Augusto Marcondes de ALMEIDA *

incidência, são dimensionados os serviços de Pré-natal e leitos de maternidade, bem como, é apurada a qualidade destas atividades.

Define-se "risco gravídico" como sendo a oportunidade a agravos: físicos, psiquicos e sociais a que estão expostos a gestante e o feto.

Não sendo a gestação um estado de normalidade fisiológica e năo sendo também um estado patológico, deve ser encarada como um estado especial onde o comportamento físico, psíquico e social da mulher está submetido a condições especiais consideradas como próprias do estado gravidico.

Nesta situação, passa a mulher a viver um risco próprio da gestação classificado em baixo, médio e alto risco não havendo a possibilidade de excluí-1o, pois, ao risco comum a que está exposto todo individuo, acrescenta-se o do estado gravídico.

$\mathrm{Na}$ definição de alto risco, alguns autores têm sugerido parâmetros que se restringem a algumas variáveis, as quais, se bem importantes, não refletem a totalidade de fatores que podem influir sobre a gravidez.

Assim EFFER 4 refere-se a 3 fatores sendo: 1) pré eclampsia grave, 2) retardo do crescimento uterino e 3) parto em gra-

Da Disciplina de Higiene Materna, do Departamento de Prática de Saúde Pública da Faculdade de Saúde Pública da USP - Av. Dr. Arnaldo, 7i15 - Săo Paulo, \$. P., Brasil.

* Convém assinatar que o conceito de "risco gravidico" nơo Indica necessariamente risco de obito. Se bem que este esteja presente, geralmente, o risco afeta desvios de saúde materna ou fetal. 
CIARI Jr., C. \& ALMEIDA, P. A. M. de - Elementos de avaliação do "risco gravídico". Rev. Saúde pübl., S. Paulo, 6: $57-78,1972$.

videz prematura. No entanto, acreditamos que todas as variáveis devam ser levadas em consideração dado o fato, já assinalado, que mesmo as de menor importancia, ao se associarem a outras, podem ser determinantes de maior risco.

Ao se avaliar o "risco gravídico" devese ter em conta os grupos de gestantes mais expostos a apresentarem complicações e as variáveis que possam estar presentes para determiná-1o, seja atuando sobre todo o grupo gestante, seja atuando em parte dele.

Assim, este risco cresce na medida em que as necessidades de serviços não atendam à demanda, atuando isto sobre todo o grupo.

Por outro lado, a variável pode atuar apenas sobre parte do grupo, como por exemplo, gestantes portadoras de uma moléstia como diabete que estão expostas a um risco maior do que as não portadoras.

Evidencia-se entāo a importância do risco relativo, isto é, aquele a que estão expostas gestantes de uma determinada categoria, em relação a outro grupo com outras características.

Durante a gravidez, ao avaliar o risco, é necessário também considerar não só as diferentes variáveis que determinam o risco, mas principalmente a importância de cada uma delas, ou seja, a influência que exercem sobre o desenvolvimento da gravidez.

Se por um lado uma variável isolada pode ser determinante de um risco maior, por outro a associação de variáveis, mesmo não muito importantes, podem levar ao alto risco. Yunes 10 demonstrou este fato analisando as complicaçōes em mulheres de paridade crescente. A Organização Mundial da Saúde 7 enfatiza a importância do número de gestações em relação ao aumento de mortalidade materna.
Diversos trabalhos têm demonstrado a importância de fatores determinantes de risco relativamente a moléstias próprias da gestaçăo e as que a ela se associam (Davies ${ }^{3}$, Slowinsky ${ }^{8}$, Beard $^{1}$ e Bertora ${ }^{2}$ ).

O "risco gravídico" deve ser encarado em seus dois aspectos, ou seja: o risco materno e o fetal. Por suas características a presença de fatores que elevam o risco materno sempre determina uma correspondente elevação do risco fetal e em contra partida o risco fetal pode crescer sem afetar o risco materno.

Segundo SzxLo ${ }^{9}$, o estudo de riscos associađos à condição materna revela que o feto também é envolvido nele refletindo-se no aumento de taxas de prematuridade, mortalidade perinatal e mesmo na infantil tardia.

Finalmente o "risco gravídico" pode ser variável em sua intensidade durante a mesma gestação, em função do progra. ma de atenção desenvolvido em torno da mãe ou do feto.

Por suas características a gravidez é condição que permite a realização de estudos prospectivos e, portanto, o esta. belecimento de parâmetros relativamente fixos para determinar o "risco gravídico" permitirão acompanhar uma coorte e avaliar com rigor as alterações que cada um deles determina no curso normal da gestação. No entanto, a análise retrospectiva de casos, se bem mais trabalhosa, permite uma visão clara do problema.

Procuramos avaliar, através do estudo retrospectivo de 62 óbitos, as condições maternas precedentes ao evento letal e o grau de "risco gravídico" a que estava exposta cada uma delas. Fizemos também uma tentativa de grupar os fa. tores do risco e de quantificá-los por tabela numérica. 
CIARI Jr., C. \& ALMEIDA, P. A. M. de - Elementos de avaliaçăo do "risco gravídico". Rev. Saú-

de públ., S. Paulo, 6: 57-78, 1972.

\section{MATERIAL E MÉTODOS}

Para analisar os 62 óbitos e verificar retrospectivamente os niveis de risco a que estariam expostas estas gestantes procuramos estabelecer alguns fatores de avaliação do "risco gravídico". Dividimos os fatores em 3 grupos fundamentais: clínico, social e de enfermagem na intenção de abranger todos os elementos que direta ou indiretamente atuam sobre a Saúde Materna.

1) Avaliação Clínica

1.1 Idade da gestante

1.2 Cor

1.3 Antecedentes familiares

1.4 História obstétrica

N.* de gestações e partos

Periodo interpartal

Evolução de gestaçōes anterio. res

gravidez

parto

puerpério

1.5 Intercorrências obstétricas

1.6 Moléstias próprias da gestação

1.7 Moléstias e desvios associados à gestação

1.8 Avaliação nutricional

1.9 Risco genético

1.10 Recursos subsidiários

1.11 Situação psicológica

2) Avaliação social

2.1 Nível sócio-econômico

2.2 Características culturais

2.3 Disponibilidade de serviços de Prenatal e Maternidade
3) Avaliação de enfermagem

3.1 Aceitação de serviços

3.2 Início da consulta

\subsection{Freqüência}

Na avaliação clínica residem as mais significativas causas de aumento de risco porém são as mais facilmente controláveis por adequados programas de Saúde Materna.

Na avaliação social situam-se os fatores que se bem, facilmente identificáveis, são de difícil controle por envolverem não só mudanças a serem determinadas no comportamento das pessoas como também fatores de desenvolvimento econômico, educacional, etc.

Finalmente, a avaliação de enfermagem presta-se para medir o grau de disponibilidade da gestante para aceitar ? controle da gestação.

Evidentemente os 3 grupos de fatores se interligam; contudo a ação criteriosa da equipe de prenatal faiclmente os analisará em conjunto.

Um dos problemas que surge no esta belecimento dos níveis de "risco graví. dico" é o critério para sua avaliação. Mesmo que os fatores usados sejam iguais, varia a interpretação dada por equipes diferentes. $\mathrm{Na}$ tentativa de uniformizar o valor do nível, procuramos quantificá-lo numericamente à semelhança do proposto por Apgar na avaliação da vitalidade do recém-nascido.

Propomos duas tabelas de notas dependendo das possibilidades do serviço de pré-natal. Na primeira, leva-se em consideração as 3 variáveis representadas pelos grupos de fatores, ou seja, clínico - social - de enfermagem. Na segunda, considerando a frequiência com que os serviços não contam com enfer- 
CTARI Jr., C. \& ALMEIDA, P. A. M. de - Elementos de avaliação do "risco gravídico". Rev. Saúde públ., S. Paulo, 6: 57-78, 1972.

meiras, propomos a utilização de apenas 2 variáveis: clínica e social. No entanto, é de se notar a necessidade de utilizar, sempre que possivel, os 3 grupos de fatores, o que pode ser feito com facilidade acompanhando-se o registro de consultas. A nota em cada grupo de fatores deve ser atribuída de acordo com os prognósticos clínico, social e de enfermagem feitos pelos examinadores. Na elaboração das Tabelas 1 e 2 atribuímos à nota o peso 3 para $o$ grupo clínico, 2 para o social e 1 para o de enfermagem. $O$ valor das notas é de $0-1-2$.

\section{TABLA 1}

Risco gravídico com 3 variáveis - Clínico - Social - de Enfermagem

Valor das notas $0-1-2$

Clínico peso 3

Social peso 2

Enfermagem peso 1

Multiplicar a nota dada em cada variável pelo peso correspondente

\section{Variáveis}

$\begin{array}{llllllllllllllllllllllllllll}\mathrm{C} & 0 & 0 & 0 & 0 & 0 & 0 & 0 & 0 & 0 & 1 & 1 & 1 & 1 & 1 & 1 & 1 & 1 & 1 & 2 & 2 & 2 & 2 & 2 & 2 & 2 & 2 & 2\end{array}$

\begin{tabular}{llllllllllllllllllllllllllllll}
$\mathrm{X}_{3}$ & $\mathrm{~S}$ \\
\hline & 0 & 0 & 0 & 1 & 1 & 1 & 2 & 2 & 2 & 0 & 0 & 0 & 1 & 1 & 1 & 2 & 2 & 2 & 0 & 0 & 0 & 1 & 1 & 1 & 2 & 2 & 2
\end{tabular}

$\begin{array}{lllllllllllllllllllllllllllllll}\mathbf{X}_{2} & \mathbf{E} & 0 & 1 & 2 & 0 & 1 & 2 & 0 & 1 & 2 & 0 & 1 & 2 & 0 & 1 & 2 & 0 & 1 & 2 & 0 & 1 & 2 & 0 & 1 & 2 & 0 & 1 & 2\end{array}$

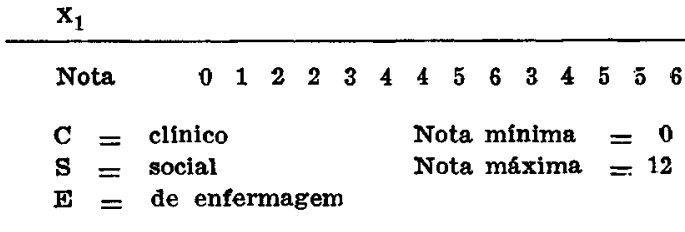

\section{T A BEI A 2}

Risco gravídico com 2 variáveis - Clínico - Social

Valor das notas $0-1-2$

Clínico peso 3

Social peso 2

Multiplicar a nota dada em cada variárel pelo peso correspondente

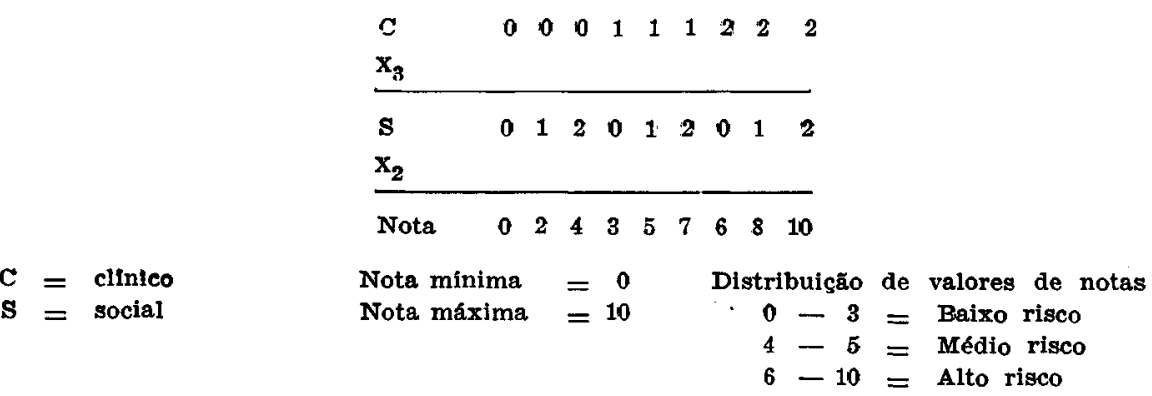


CIARI Jr., C. \& ALMEIDA, P. A. M. de - Elementos de avaliação do "risco gravídico". Rev. Saúde públ., S. Paulo, 6: 67-78, 1972.

Consideramos que a distribuição dos valores das notas segundo os níveis de risco deva ser:

$$
\begin{aligned}
& 0-3=\text { Baixo risco } \\
& 4-6=\text { Médio risco } \\
& 7-12=\text { Alto risco }
\end{aligned}
$$

Na Tabela 1 temos as associações dos valores que multiplicados pelos respectivos pesos determinam a nota.

Para a Tabela 2 de duas variáveis os critérios são os mesmos mudando apenas os valores extremos das notas e conseqüentemente sua distribuição, que no caso é:

$$
\begin{aligned}
& 0-3=\text { Baixo risco } \\
& 4-5=\text { Médio risco } \\
& 6-10=\text { Alto risco }
\end{aligned}
$$

Na Tabela 2 temos as associações dos valores com duas variáveis.

Com a finalidade de estabelecer uma relação entre o grau de "risco gravídico" e o evento "obito materno" foram tomados, retrospectivamente, casos de óbitos maternos e, através de entrevista com o médico atestante, o médico assistente e familiares, estabeleceu-se a história obstétrica das mulheres. Todas as vezes em que dados considerados importantes faltavam ou eram obscuros o caso era abandonado. Assim conseguimos relacionar 62 óbitos onde os fatores de risco nomeados em nossa classificação, se preserites, seriam identificados. $\mathrm{Na}$ avaliação social determinamos o nível sócio-econômico utilizando o grau de instrução, renda familiar, profissão do chefe da familia e habitação. Classificamos 3 grupos (I-II-III) correspondendo a progressiva elevação do nível sócioeconômico. Nas características culturais procuramos saber da existência de hábitos especiais em relação à gestação. Nas disponibilidades de serviços levamos em conta não só a existência de pré-natal e leitos de maternidade como também facilidades a seu acesso. Porém, neste aspecto, o que aparece em nosso estudo é efetivamente o local de assistência da mulher quando ocorreu o evento que determinou o óbito. Pareceu-nos mais interessante ressaltar a assistência hospitalar, domiciliar ou de urgência que teve durante o processo.

$\mathrm{Na}$ avaliação de enfermagem consideramos importante a frequiencia ao prenatal e quando possível a idade da gra. videz na primeira consulta.

Na Tabela 3 respeitamos integralmente as determinações da Classificação Internacional de Doenças da OPS e OMS, 8." revisão 1965, para a listagem das causas de óbito. Porém nas demais, para mais fácil apreciação, grupamos os óbitos em 4 causas básicas: Hemorragia, Toxemia, Infecção, Moléstias associadas e através delas avaliamos quanto um fator de risco estava presente em cada uma.

Outro aspecto que nos afastou da Classificação Internacional de Doenças foi aquele referente a considerar os casos de descolamento prematuro de placenta como pertencente ao grupo de toxemia e não de hemorragia. Isto, porque, para - clínico esta entidade obstétrica ligase muito mais ao fator toxemico do que propriamente hemorrágico.

\section{R E S U L T A D O S}

Na Tabela 3 observamos a distribuição dos óbitos por causas referidas à Classificação Internacional de Doenças. Nela estão incluídas não só as causas obstétricas como também as associadas.

Nas Tabelas 4, 5, 6 e 7 estão distribuídos todos os casos segundo o grupo de causas e os fatores de risco medidos por nós. 
CIARI Jr.. C. \& ALMEIDA, P. A. M. de - Elementos de avaliação do "risco gravídico". Rev. Saú de pübl., S. Paulo, 6: 57-78, 1972.

TABELA 3

Distribuição dos óbitos por causa

\begin{tabular}{|c|c|c|}
\hline * & Causa & N.o \\
\hline 631.5 & Gravidez ectópica & 3 \\
\hline 632.1 & Desprendimento prematuro da placenta & 7 \\
\hline 637.1 & Eclâmpsia & 9 \\
\hline 642.0 & Abortamento infectado & 1 \\
\hline 642.1 & Abortamento e hemorragia & $\mathbf{3}$ \\
\hline 651 & Placenta prévia - Parto & 3 \\
\hline 652 & Parto e retençao de placenta & 4 \\
\hline 653 & Parto hemorragia pós parto & 8 \\
\hline 659 & Parto e rotura de útero & 1 \\
\hline 662 & Anestesia sem complicação de parto & 1 \\
\hline 670 & Infecção do parto & 2 \\
\hline 675 & Discrasia sangüínea pós parto & 1 \\
\hline 582 & Nefropatia crônica & 11 \\
\hline 429 & Cardiopatia & 9 \\
\hline
\end{tabular}

\footnotetext{
* A numeração e os títulos das causas de obitos maternos foram feitos de acordo com a Classificação Internacional de Doenças da Organização Pan Americana de Saúde e Organizaçăo Mundial da Saúde $-8 . *$ Revisăo - 1965.
}

Na Tabela 8 verificamos a proporção de óbitos segundo o grupo de causas e nível de risco onde se nota a predominância de gestantes classificadas como alto risco $(75,80 \%)$.

Na Tabela 9 juntamos os óbitos segundo o grupo de causas e o número de consultas de pré-natal. Nota-se que $62,90 \%$ das gestantes não tinham se submetido a nenhuma consulta de pré-natal. Por outro lado, apenas 3 gestantes $(4,83 \%)$ submeteram-se a um número razoável de consultas.

Ao observarmos a Tabela 10 notamos elevado número de pacientes $(42-67,73 \%$ ) que foram atendidas em Hospital-Urgência e Domicilio + Hospital-Urgência.

Na Tabela 11 relacionamos o grupo de causas de óbitos com o nível sócioeconômico, chegando à conclusão que dos 62 óbitos estudados $46(74,19 \%)$ si- tuaram-se em gestantes de nivel social I e apenas em 3 dos 6 bitos as gestantes pertenciam ao nível sócio-econômico III, restando 13 no grupo II.

Ao relacionarmos as moléstias pró. prias e associadas da gestação com o grupo de causas de óbitos, estabelecemos a Tabela 14 onde observamos que 31 pacientes, isto é, $50 \%$ somam as 2 complicações de gravidez, associada e própria da gestação.

Verificou-se que $22,58 \%$ dos óbitos ocorreram em mulheres que não apresentavam patologia própria ou associada. No entanto, nenhuma das gestantes que apresentava moléstia associada o fazia sem ter concomitantemente uma moléstia própria. Por outro lado a associação de presença de moléstia própria com moléstia associada não é tão frequiente como o contrário. 
CIARI Jr., C. \& ALMEIDA, P. A. M. de - Elementos de avaliação do "risco gravídico". Rev. Saíde públ., S. Paulo, 6: 57-78, 1972.

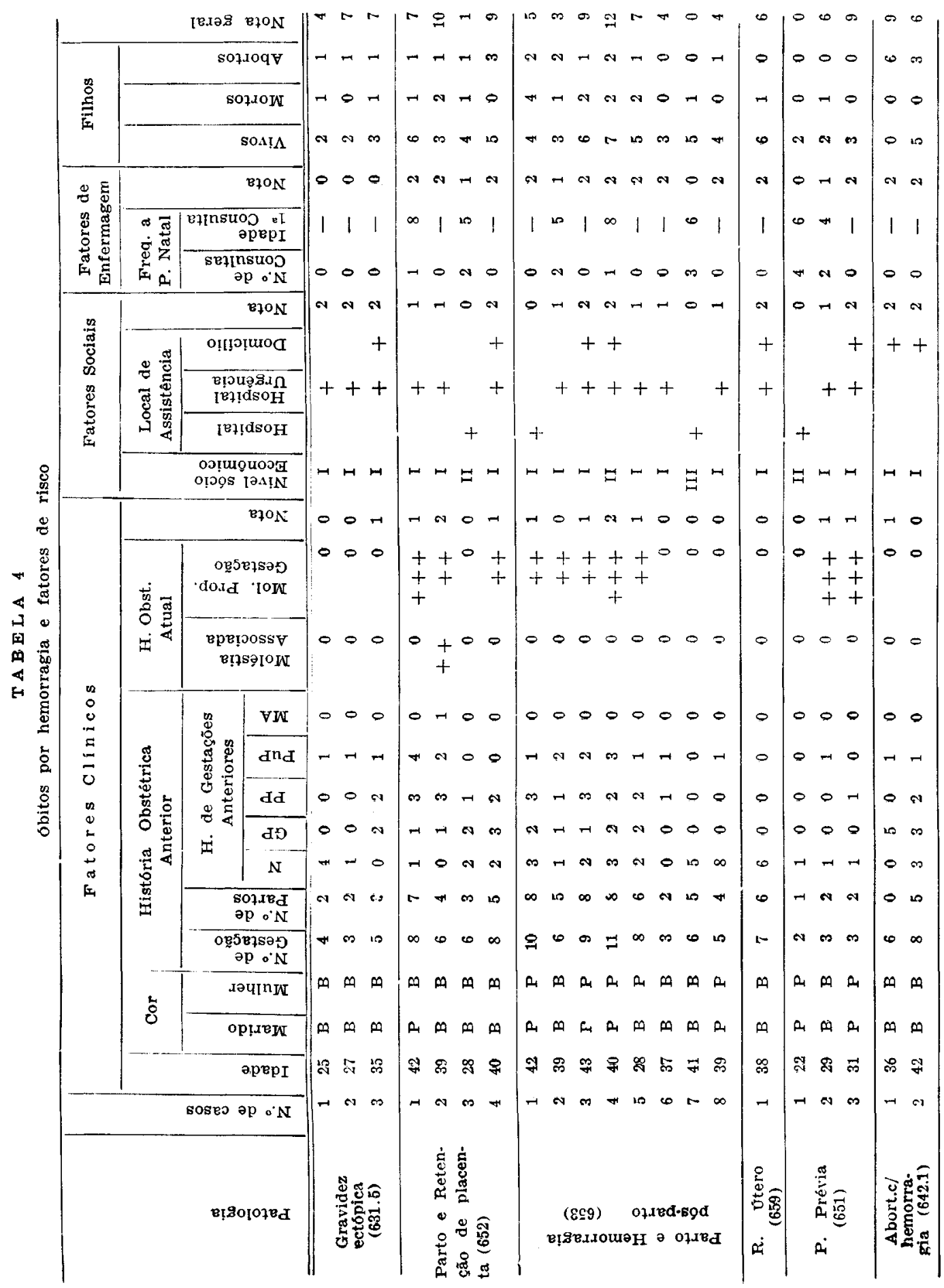


CIARI Jr., C. \& ALMEIDA, P. A. M. de - Elementos de avaliação do "risco gravídico". Rev. Saúde públ., S. Paulo, 6: 57-78, 1972.

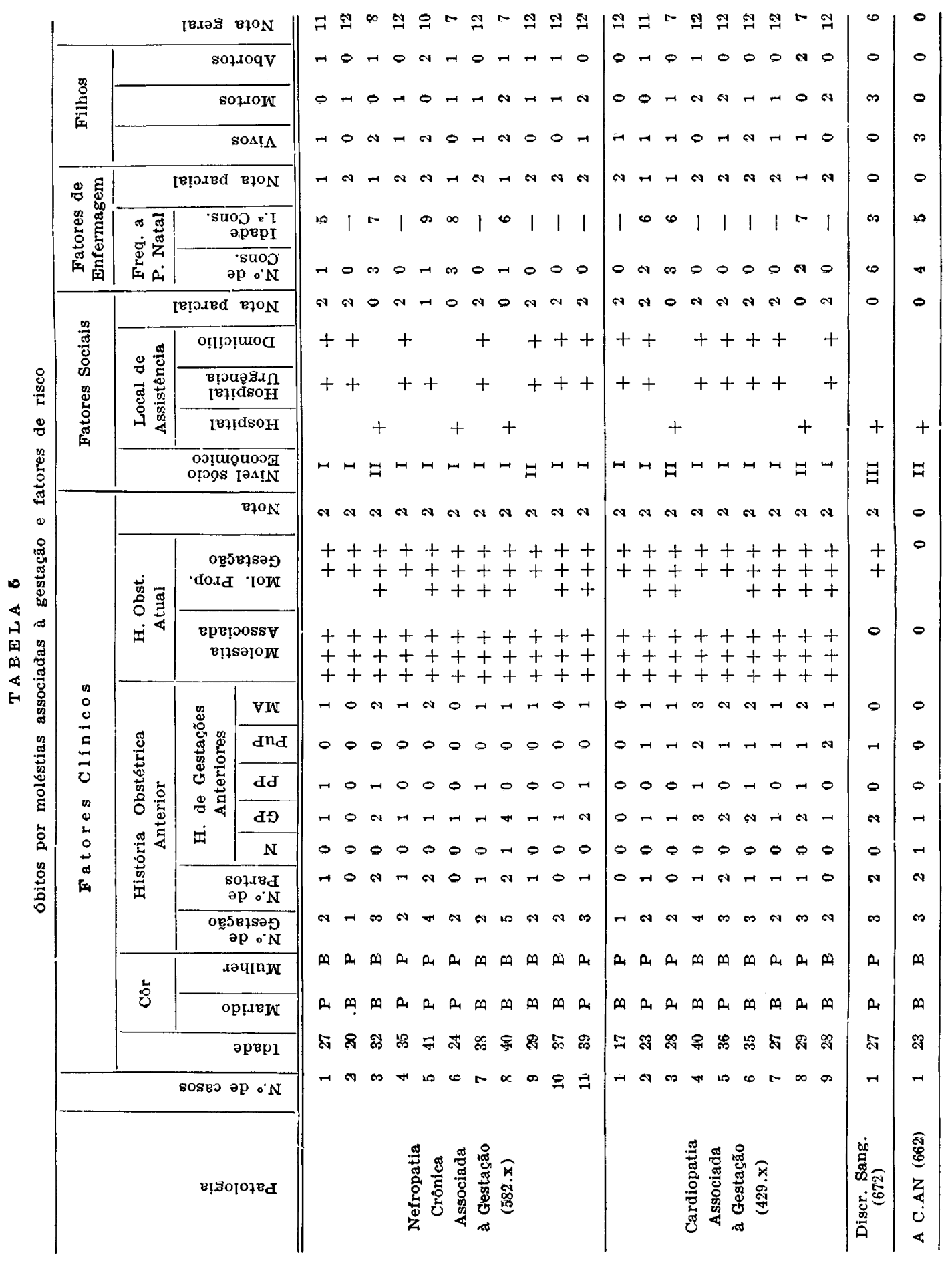


CIARJ Jr., C. \& ALMEIDA, P. A. M. de - Elementos de avaliação do "risco gravídico". Rev. Saride públ., S. Paulo, 6: 57-78, 1972.

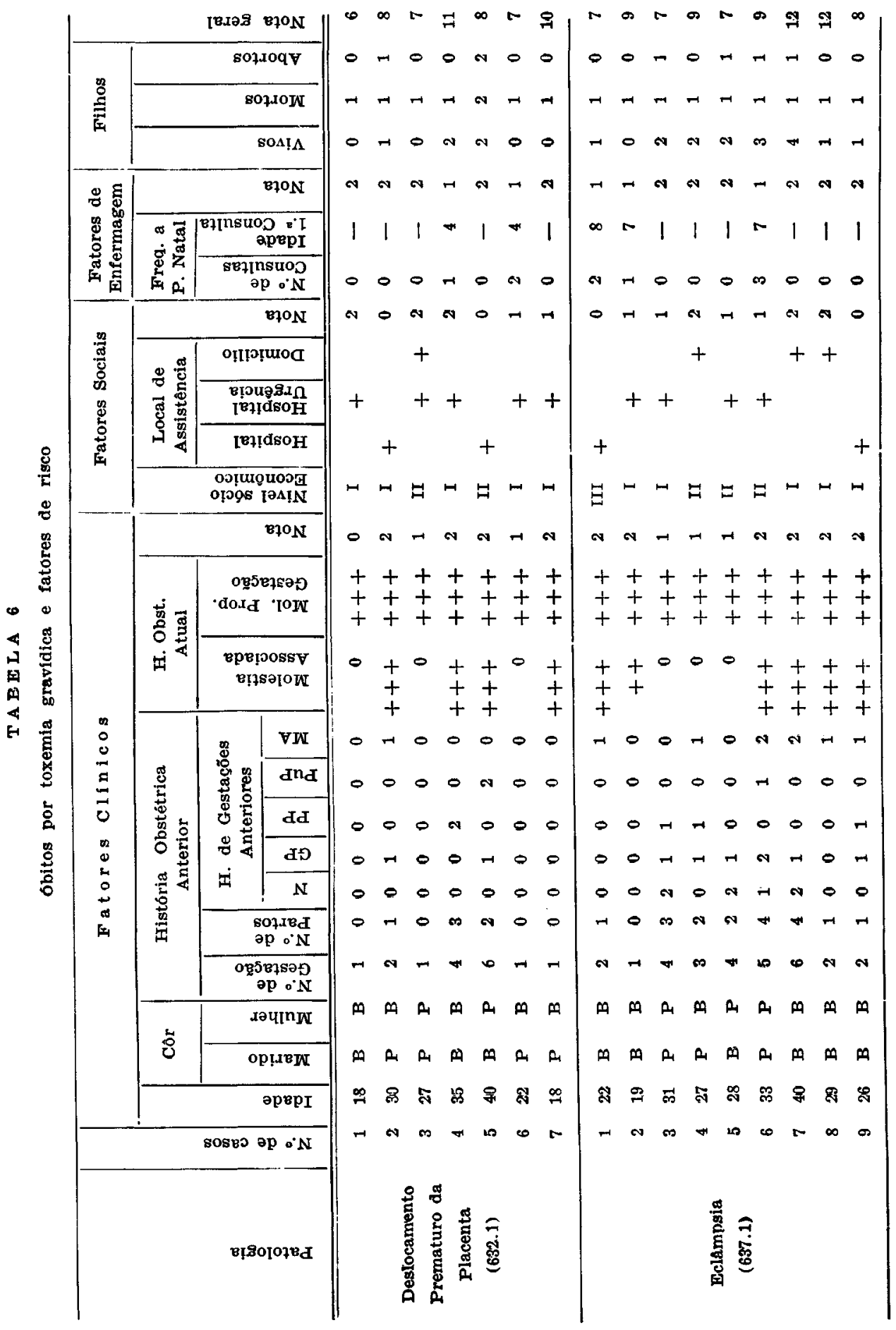


CIARI Jr., C. \& ALMEIDA. P. A. M. de - Elementos de avaliação do "risco grarídico". Rev. Saú. de puibl., S. Paulo, 6: 57-78, 1972.

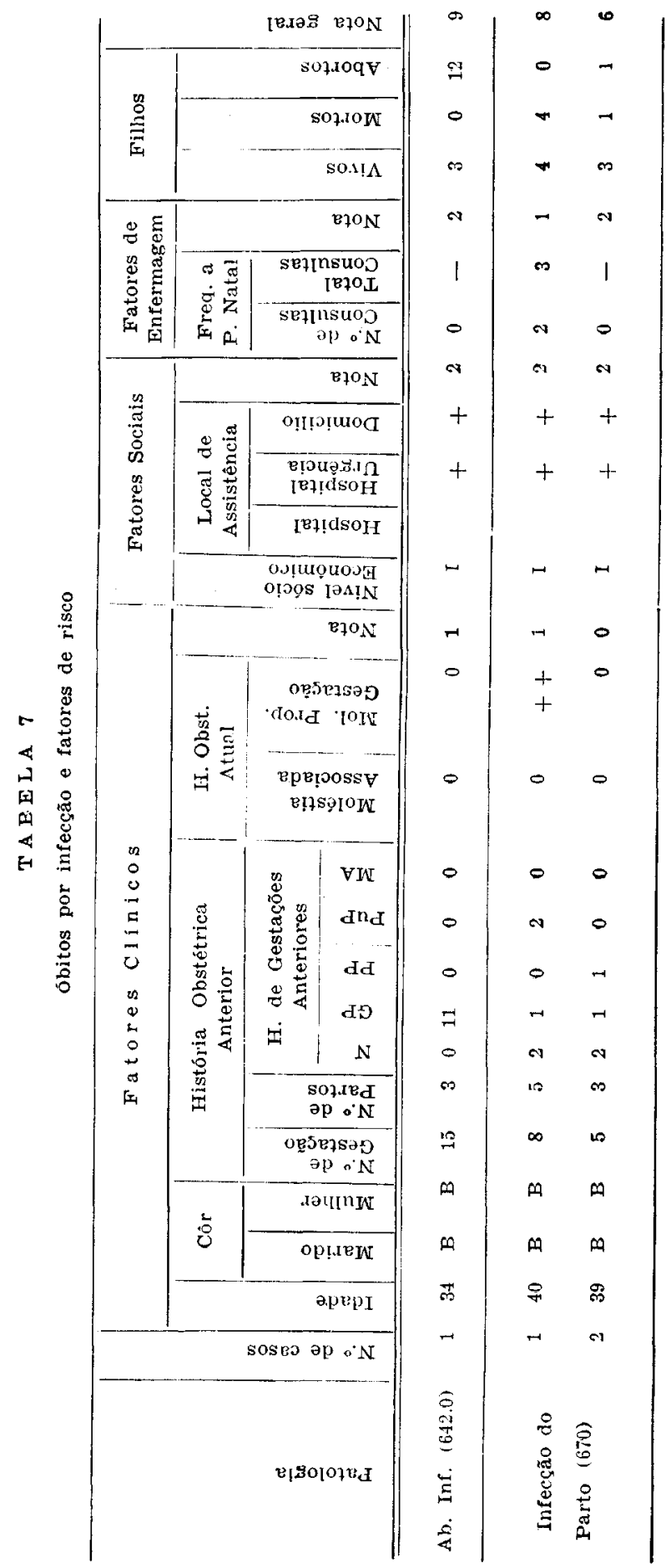


CIARJ Jr., C. \& ALMEIDA, P. A. M. de - Elementos de avaliação do "risco gravídico". Rev. Saúde puibl., S. Paulo, 6: 57-78, 1972.

TA B E L A 8

obitos segundo causa e nível de risco

\begin{tabular}{|c|c|c|c|c|c|c|c|c|}
\hline \multirow{3}{*}{ Causas } & \multirow{2}{*}{\multicolumn{2}{|c|}{ Total }} & \multicolumn{6}{|c|}{ Nivel de risco } \\
\hline & & & \multicolumn{2}{|c|}{ Baixo } & \multicolumn{2}{|c|}{ Médio } & \multicolumn{2}{|c|}{ Alto } \\
\hline & N.o & $\%$ & N. ${ }^{\circ}$ & $\%$ & N.o & $\%$ & $\mathrm{~N} .{ }^{\circ}$ & $\%$ \\
\hline Hemorragia & 21 & $\begin{array}{c}100 \\
(33,97)\end{array}$ & 4 & 19,04 & 7 & 33,33 & 10 & 47,61 \\
\hline Toxemia & 16 & $\begin{array}{c}100 \\
(21,80)\end{array}$ & - & - & 1 & 6,25 & 15 & 93,75 \\
\hline Infecção & 3 & $\begin{array}{ll} & 100 \\
4 \quad(4,83)\end{array}$ & - & - & 1 & 33,33 & 2 & 66,66 \\
\hline Mol. associadas & 22 & $\begin{array}{c}100 \\
(35,48)\end{array}$ & 1 & 4,54 & 1 & 4,54 & 20 & 90,90 \\
\hline TOTAL & 62 & 100 & 5 & 8,06 & 10 & 16,14 & 47 & 75,80 \\
\hline
\end{tabular}

A associação dos grupos de moléstias e a idade da gestante dados pela tabela 15 revela uma predominância das hemorragias no grupo de idade mais elevada, 36 a 45 anos, fato que não se define muito claramente nos outros grupos, se bem que a tendência geral de todos os casos seja manter uma proporcionalidade maior nos grupos de mais idade. O único fato estranhável é a presença de uma proporção alta de óbitos nas idades mais baixas no grupo de toxemia. Na Tabela 15 verificam-se óbitos por descolamento prematuro de placenta em mulheres de idade mais baixa, enquanto que nos óbitos por eclâmpsia a idade é mais alta, contrapondo-se isto ao comumente observado.

Analisando os dados expostos na Tabela 16 nota-se que a concentração de óbitos ocorreu entre mulheres de baixa paridade $\mathrm{e}$, isto, provàvelmente se fez às custas do grande número de óbitos por toxemia e moléstias associadas.

\section{I S CUSS A O}

A determinação da prioridade de atenção à maternidade funda-se em que o grupo populacional gestante passa a ser, relativamente ao grupo de não gestan tes, mais exposto a ter problemas de saúde. Disto decorre a necessidade dos programas se destinarem a atingir porcentagem alta de gestantes (em torno de $85 \%$ ). Mais especificamente, na elaboração dos programas de Saúde Materna, deve-se levar em conta os fatores que de forma especial determinam o "risco gravídico". 
CIARI Jr., C. \& ALMEIDA, P. A. M. de - Elementos de avaliação do "risco gravídico". Rev. Saü. de pübl., S. Paulo, 6: 57-78, 1972.

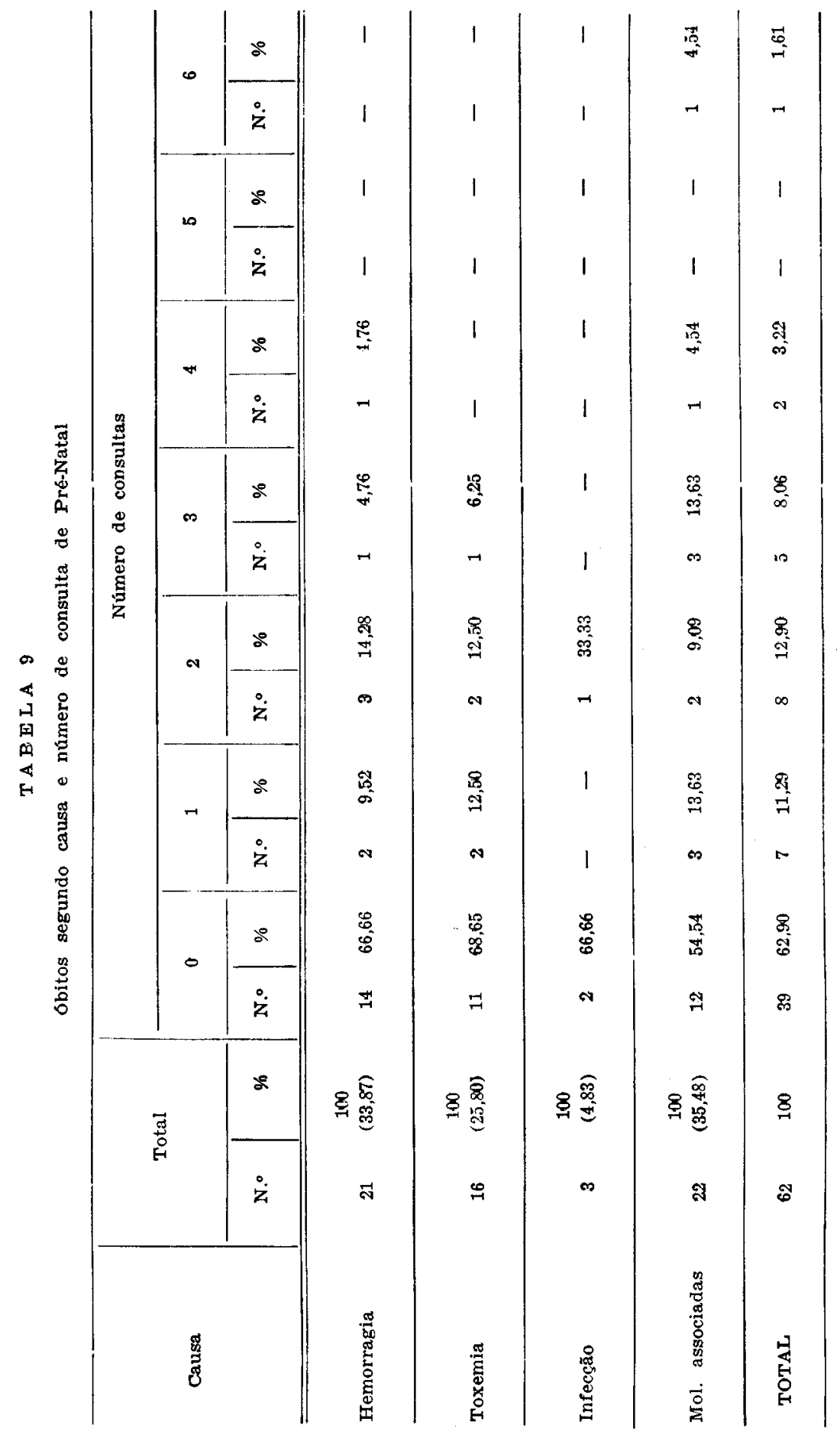


CIARI Jr., C. \& ALMEIDA, P. A. M. de - Elementos de avaliaçăo do "risco gravíaico" Rev. saúde puibl., S. Paulo, 6: 57-78, 1972.

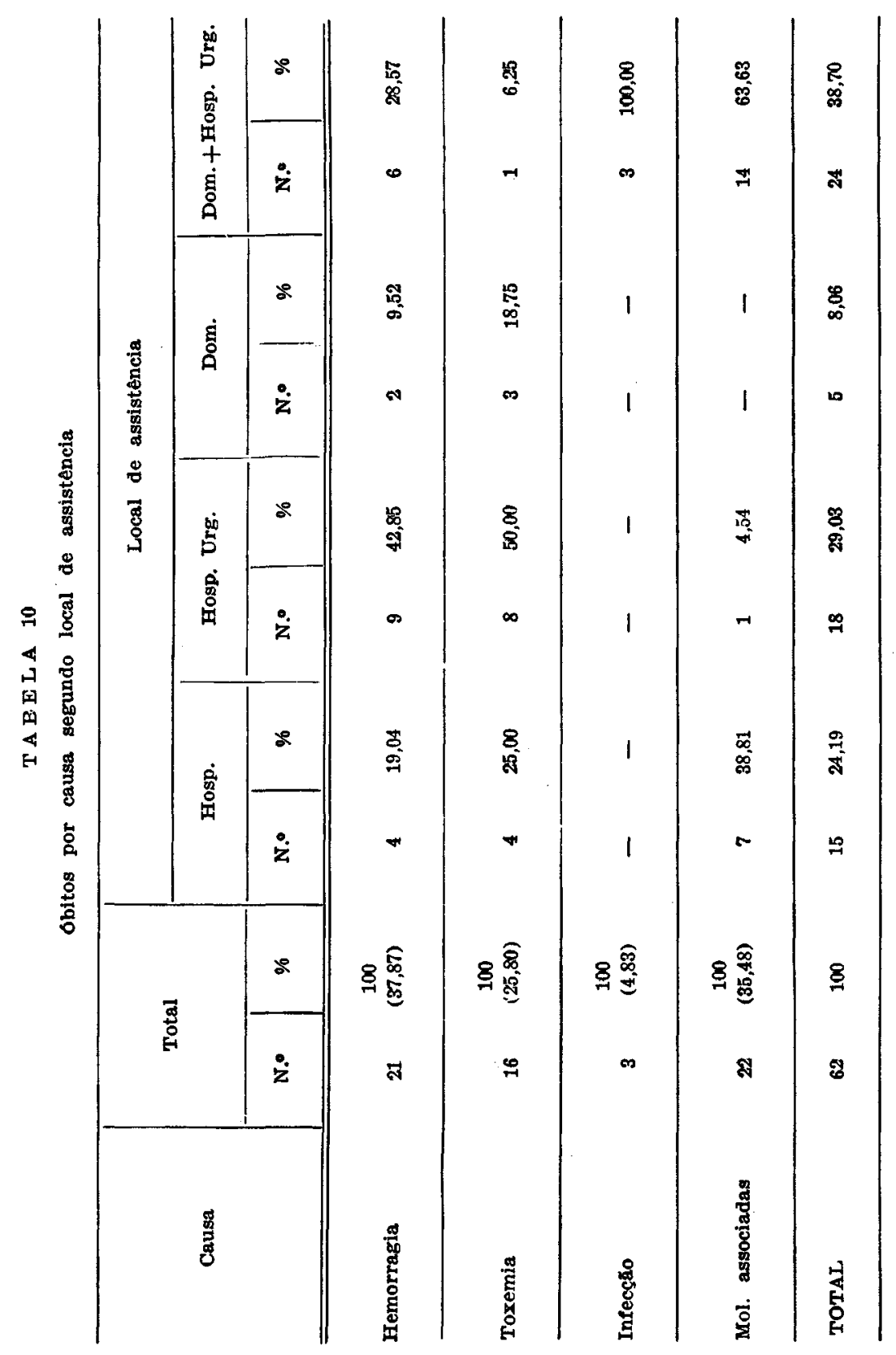


CIARI Jr., C. \& ALMEIDA, P. A. M. de - Elementos de avaliação do "risco gravídico". Rev. Saú. de públ., s. Paulo, 6: 57-78, 1972.

TABELA 11

óbitos por causa segundo nível sócio-econômico

\begin{tabular}{|c|c|c|c|c|c|c|c|c|}
\hline \multirow{3}{*}{ Causa } & \multirow{2}{*}{\multicolumn{2}{|c|}{ Total }} & \multicolumn{6}{|c|}{ Nivel socio econômico } \\
\hline & & & \multicolumn{2}{|c|}{ I } & \multicolumn{2}{|c|}{ II } & \multicolumn{2}{|c|}{ III } \\
\hline & N.॰ & $\%$ & N.o & $\%$ & N.o & $\%$ & N.० & $\%$ \\
\hline Hemorragia & 21 & $\begin{array}{c}100 \\
(37,87)\end{array}$ & 17 & 80,95 & 3 & 14,28 & 1 & 4,76 \\
\hline Toxemia & 16 & $\begin{array}{c}100 \\
(25,80)\end{array}$ & 10 & 62,50 & 5 & 31,25 & 1 & 6,25 \\
\hline Infecção & 3 & $\begin{array}{c}100 \\
(4,83)\end{array}$ & 3 & 100,00 & - & - & - & - \\
\hline $\begin{array}{l}\text { Mol. asso- } \\
\text { cladas }\end{array}$ & 22 & $\begin{array}{c}100 \\
(35,48)\end{array}$ & 16 & 72,72 & 5 & 22,72 & 1 & 4,54 \\
\hline TOTAL & 62 & 100 & 46 & 74,19 & 13 & 20,96 & 3 & 4,83 \\
\hline
\end{tabular}

O conhecimento da incidência de fatores determinantes de risco a que está exposto o grupo gestante, orienta no estabelecimento de prioridade e determina atividades tendentes ao controle destes fatores. Em nosso meio, por exemplo, um dos determinantes de risco é o baixo número de consultas de prénatal por gestante, sendo necessário não só o aumento da oferta de serviços como também um adequado programa de educação para a saúde das gestantes. Convém assinalar que a toxemia, moléstia prevenível durante a gravidez foi a que apresentou maior proporção de mulheres de alto risco. No grupo de hemorragia nota-se que houve uma proporção razoável de mulheres de baixo risco o que parece demonstrar que o óbito por esta causa necessariamente pode não envolver um risco prévio avaliável.

A Tabela 9 demonstra que em nossos casos, $62,90 \%$ das mulheres não tinham sido consultadas no pré-natal. Este número se eleva a $87,09 \%$ se considerarmos como um nível muito baixo de assistência até 2 consultas. Nota-se ainda uma evidente relação entre o maior número de consultas e menor casos de óbito.

Devido à alta porcentagem de mulheres com 0,1 ou 2 consultas de pré-natal é impossivel estabelecer adequadamente uma relação gradativa entre o número de consultas e risco. O que fica ressaltado é a alta porcentagem de mulheres que não são submetidas a assistência Pré-natal, ocasionando uma elevação de seu "risco gravídico". 
CIARI Jr., C. \& ALMEIDA, P. A» M. de - Elementos de avaliação do "risco graviđico". Rev. Saú. de públ., S. Paulo, 6: 57-78, 1972.

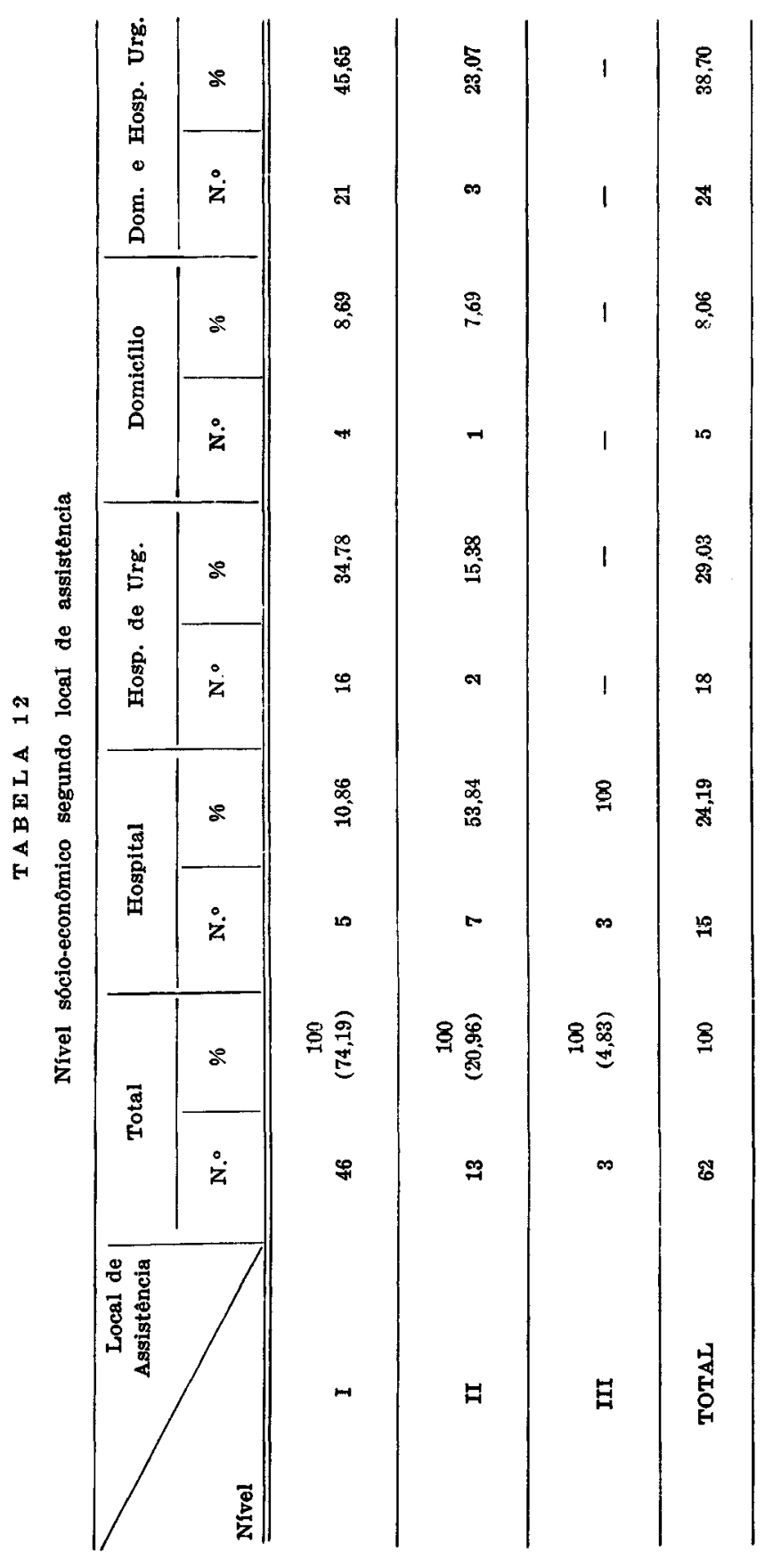


CIARI Jr., C. \& ALMEIDA, P. A. M. de - Elementos de avaliação do "risco gravídico". Rev. Saúde puibl., S. Paulo, 6: 57-78, 1972.

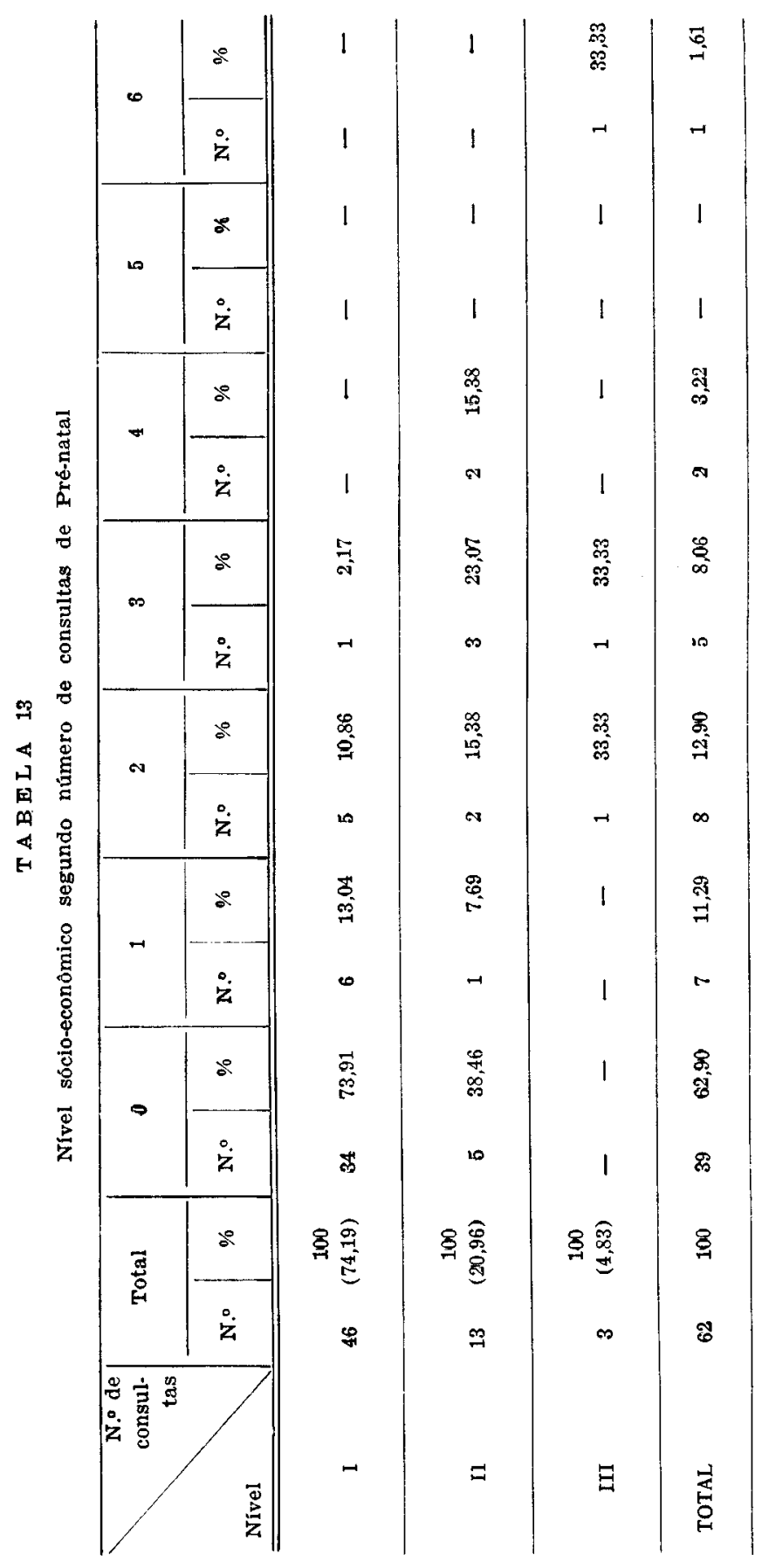


CIARI Jr., C. \& ALMEIDA, P. A. M. de - Elementos de avaliação do "risco gravídico". Rev. Saúde públ., S. Paulo, 6: 57-78, 1972.

T A B E L A 14

óbitos segundo grupo de causas e relação entre moléstias próprias e associadas da gestaçăo.

\begin{tabular}{|c|c|c|c|c|c|c|c|c|c|c|}
\hline \multirow{3}{*}{ Causa } & \multirow{2}{*}{\multicolumn{2}{|c|}{ Total }} & \multicolumn{8}{|c|}{ Relação das moléstias } \\
\hline & & & \multicolumn{2}{|c|}{ SMP + SMA } & \multicolumn{2}{|c|}{ SMP + CMA } & \multicolumn{2}{|c|}{ CMP + SMA } & \multicolumn{2}{|c|}{$\mathrm{CMP}+\mathrm{CMA}$} \\
\hline & N.० & $\%$ & N.o & $\%$ & N.o & $\%$ & N.o & $\%$ & N.o & $\%$ \\
\hline Hemorragia & 21 & $\begin{array}{c}100 \\
(33,87)\end{array}$ & 11 & 52,38 & - & $\leftarrow$ & 9 & 42,85 & 1 & 4,76 \\
\hline Toxemia & 16 & $\begin{array}{c}100 \\
(25,80)\end{array}$ & - & - & - & 一 & 6 & 37,50 & 10 & 62,50 \\
\hline Infecção & 3 & $\begin{array}{c}100 \\
(4,83)\end{array}$ & 2 & 66,66 & - & - & 1 & $\mathbf{3 3 , 3 3}$ & - & - \\
\hline Mol. associadas & 22 & $\begin{array}{c}100 \\
(35,48)\end{array}$ & 1 & 4,54 & - & - & 1 & 4,54 & 20 & 90,90 \\
\hline TOTAL & 62 & 100 & 14 & 22,58 & - & - & 17 & 27,41 & 31 & 50,00 \\
\hline $\begin{array}{l}\text { SMP - sem n } \\
\text { CMP - com n }\end{array}$ & pr & & & $\mathrm{SM}$ & $-s$ & $\begin{array}{l}\mathrm{mol} \\
\mathrm{mol}\end{array}$ & $\begin{array}{l}\text { tia } \\
\text { tia }\end{array}$ & $\begin{array}{l}\text { ociada } \\
\text { ociada }\end{array}$ & & \\
\hline
\end{tabular}

Outro fator especifico demonstrado pela Tabela 10 refere-se ao local de assistência no parto que determinou o evento óbito. Vemos que a grande proporção está naqueles que inicialmente permaneceram em domicílio e posteriormente foram removidos de urgência para a maternidade. Além disso, nota-se a grande predominância de óbitos ocorridos nos 3 grupos constituídos por chegada de urgência ao hospital, domicilio e por associação dos dois.

Outro dado importante que nos fornece a Tabela 9 é o fato de que pacientes com moléstias associadas e que, portanto, deveriam ter sido submetidas a efetivo controle pré-natal e concomi- tante internação prévia, em hospital, nos dão o maior indice de Domicílio e Hospital de Urgência, isto é, $63,63 \%$.

Outro fato a ser assinalado é a tendência atual para a procura de maternidade para dar a luz. Nos nossos casos verificamos que apenas 5 mulheres $(8,06 \%)$ deixaram de recorrer em qualquer momento a serviço hospitalar Este número coincide com os obtidos pela "Investigação Internacional de Obitos de 0 a 5 anos" " onde cerca de $85 \%$ das mulheres na cidade de São Paulo deram a luz em hospital. No entanto, entre as mulheres de alto risco, mesmo quando atendidas em hospital, a pro. porção de óbito é bastante elevada $(24,19 \%)$. 
CIARI Jr., C. \& ALMEIDA, P. A. M. de - Elementos de avaliação do "risco gravidico". Rev. Saúde públ., S. Paulo, 6: 57-78, 1972.

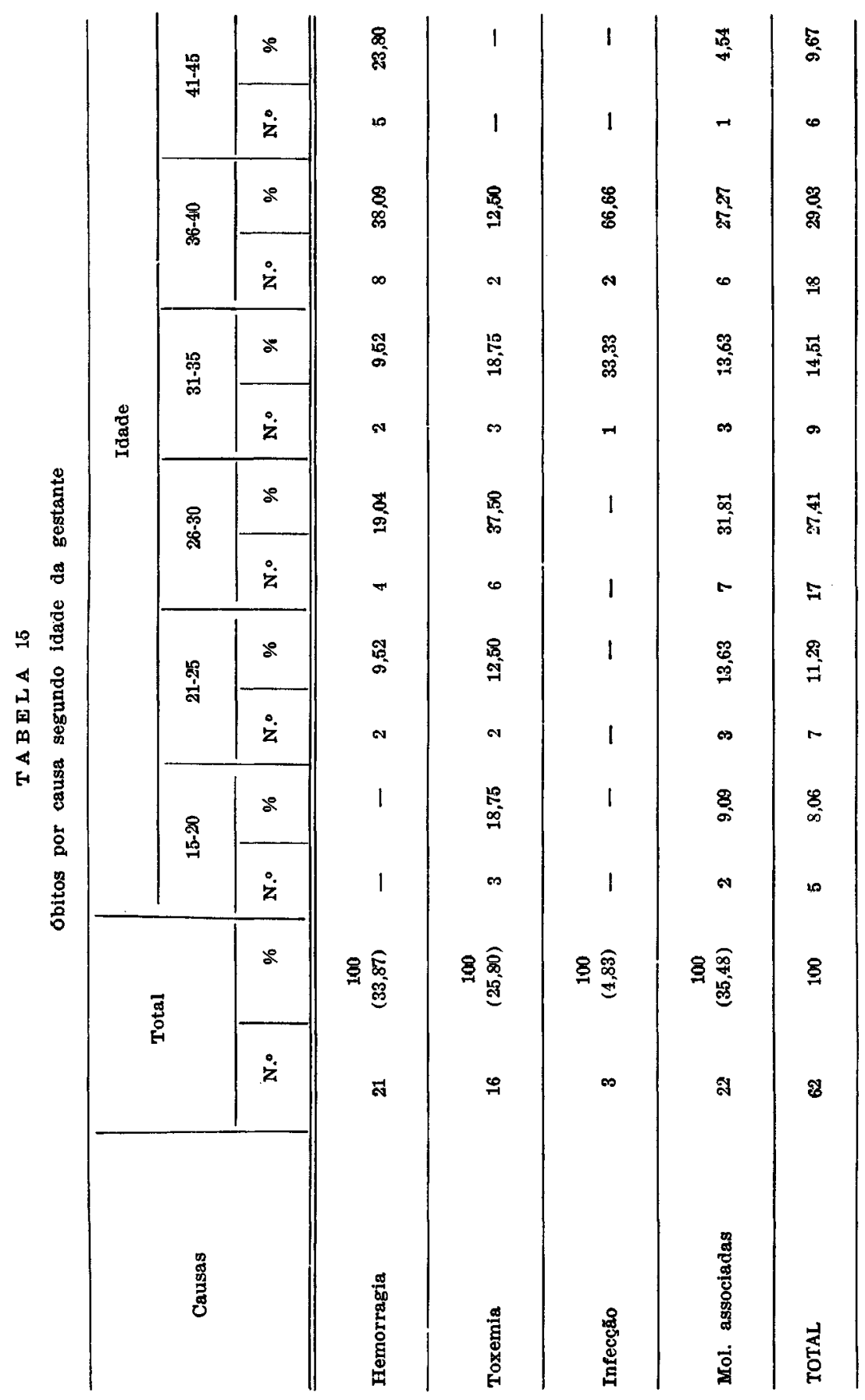


CIARI Jr., C. \& ALMEIDA, P. A. M. de - Elementos de avaliação do "risco gravíđico". Rev. Saú. de puibl., S. Paulo, 6: 57-78, 1972.

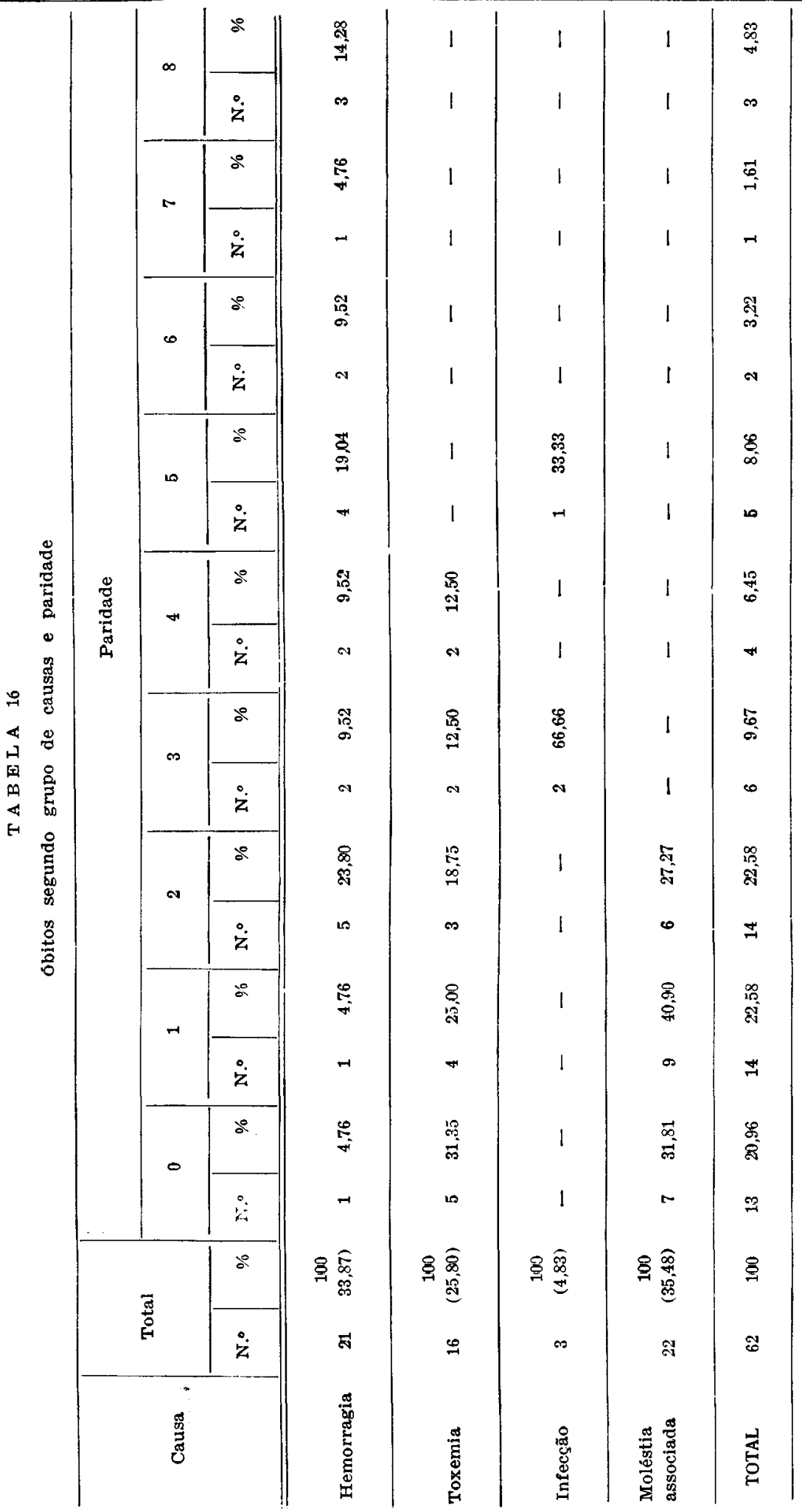


CIARI Jr., C. \& ALMEIDA, P. A. M. de - Elementos de avaliação do "risco gravídico". Rev. Saúde públ., S. Paulo, 6: 57-78, 1972.

$\mathrm{Da}$ análise dos resultados da Tabela 9 depreende-se a importância da atenção hospitalar que não pode estar restrita à assistência ao parto mas sim estender a internação dos casos de patologia da gestação.

Na Tabela 9 verifica-se evidente associação entre nível sócio-econômico baixo (grupo I) e óbitos ocorridos. Assim é que $74,19 \%$ dos óbitos estão na classe I considerada por nós menos favorecida. No entanto, a observação da Tabela 12 nos revela a grande porcentagem de muIheres do grupo I que tiveram a assistência em urgência hospitalar, domiciliar ou em associação dos dois. Nos níveis II e III, ao contrário, já se nota a elevação do porcentual das atividades em hospital.

A associação entre nível sócio-econômico e nümero de consultas é ainda mais nitida. Na Tabela 13 verifica-se que $73,91 \%$ dos casos de óbito era constituído por mulheres sem nenhuma assistência pré-natal. Neste caso situa-se a grande proporção das mulheres do grupo I. Vemos por aí que a atuação de programas deve se dirigir especialmente ao nível sócio-economico mais baixo. Mais importante ainda é a inutilidade do aumento apenas de leitos hospitalares pois, a análise destes resultados demonstra que a mortalidade permanece proporcionalmente mais alta neste grupo mesmo que recorra ao hospital. Parece-nos haver um problema de educação da gestante que deve saber procurar adequadamente os recursos de assistência.

Vemos assim que fatores de risco considerados não muito importante se cotizados com os fatores clínicos adquirem um grande significado quando se associam. Parece-nos que nível sócioeconômico é determinante de baixo número de consultas e procura inadequa- da de recursos hospitalares, resultando em alto "risco gravídico".

Outro fator a ser analisado é a idade da gestante (Tabela 15) onde se observa que a maior concentração de óbitos ocorreu no grupo 36-40 anos. No entanto, se bem haja uma tendência para au mento com a idade não foi muito níti da esta associação.

O mesmo ocorreu em relação à paridade (Tabela 16) onde se nota que neste grupo de mulheres a tendência era para poucos filhos. Isto, também, se explica por se tratar de um grupo especial e não ser uma amostra representa. tiva da ocorrência geral de óbitos obs. tétricos.

A Tabela 14 que trata da presença de moléstias associadas e próprias da gestação, parto e puerpério, como fator de risco, mostra que no grupo de hemorragia, pur se tratar de acidente da gravidez e, portanto, com pouca chance de previsão, praticamente a totalidade, não revelava qualquer patologia que pudesse estabelecer um nível de risco mais significativo. Nestes casos o nível de risco é mais determinado por outros fatores que rão os clínicos como se pode observar pela Tabela 8. Já na toxemia onde há forte associação de moléstias próprias e moléstias associadas $(62,50 \%)$ vemos que a alta porcentagem de alto risco $(93,75 \%)$ (Tabela 8) é dada por fatores clínicos. O mesmo se repete com as moléstias associadas $(90,90 \%)$ na Tabela 14 c $90,90 \%$ na Tabela 8 onde se evidencia que o fator clínico determina o risco.

Vemos assim que pela análise das tabelas o nivel de risco pode ser determinado por um fator isoladamente, como ocorre com os clínicos, porém, fora dis. to, necessita da associação de diferertes variáveis para ser significativo. Disto rẹsulta que na avaliação do "risco gravi. 
CIARI Jr., C. \& ALMEIDA, P. A. M. de - Elementos de avaliação do "risco gravídico". Rev. Saúde públ., S. Paulo, 6: 57-78, 1972.

dico" não podemos querer determiná-lo apenas enfocando o fator clínico pois, na ausência destes, a análise dos demais pode também evidenciar um risco que deve ser levađo em consideração.

\section{CONCLUSOES}

Se bem que em estudo retrospectivo, não se preste integralmente para avaliar o "risco gravídico", a análise dos resultados epresentados parece deixar clara a importância dos diferentes fatores na determinação do nível de risco. Fica evidente que os mais importantes estão situados na área clínica e para eles deve se voltar a maior atenção dos programas de Saúde Materna. No entanto os fatores sociais e de enfermagem tem participação decisiva no estabelecimento do risco, seja determinando-o diretamente, seja como contribuinte, engravecendo mais uma patologia presente.

E preciso ainda considerar que a ava liação do risco não se destina a criar serviços especiais de Saúde Materna para mulheres de "alto risco", (como o proposto por Gold \& STONe ${ }^{5}$ ) mas sim identificar fatores que determinem as prioridades para estabelecer atividades programadas que impeçam o grupo gestante de atingir um risco maior do que o já determinado pela gestação.

Estas atividades, corretamente programadas em Pré-natal, facultam ao programa hospitalar da Assistência à Maternidade uma atuação mais eficiente no sentido de reduzir não só a mortalidade materna mas, principalmente, a mortalidade perinatal que, a despeito do aumento do número de leitos de maternidade e da ocupação deles, continua alta.

Independentemente dos diferentes fa tores que ocasionaram o óbito destas 62 mulheres parece que três, embora não tão importantes como os clínicos, determinam uma elevação significativa do risco. São eles: 1) baixo nível sócio-econômico, 2) inadequada frequiência ao Prénatal e, 3) uso incorreto dos recursos hospitalares. Mesmo que estejam intima. mente ligados acreditamos que os dois últimos poderão ser controlados por uma adequada programação de Saúde Materna, cobrindo a demanda para as consultas e partos esperados bem como desenvolvendo atividades de educação principalmente sobre o grupo fértil de mulheres.

RSPSP-117

Ciari JR., C. \& Almeida, P. A. M. de [Evaluation of pregnant risk]. Rev. Saúde públ., S. Paulo, 6: 57-78, 1972.

Summary: Some basic concepts which define the "pregnant risk" are establishod. A classification of the elements which must be considered in the risk establishement is proposed. The purpose of quantifying the risk evaluation and based on the classification factors marks are attributed whose total amount dietermines a value which measures the "pregnant risk" intensity. Based upon these values, 62 maternal death are studied retrospectively and distributed in tables in which different factors are associated. In conclusion it is verified that an adequate program of Maternal Hialth is necessary not only to attend the pregnant women during the prenatal period as also to give hospital care. The death analysis and the factors that determine the high-risk suggest elements for the elaboration of Maternal Health programs.

UNITERMS: Pregnancy* ${ }^{*}$ Maternal care*; Pregnant risk*. 
CIARI Jr., C. \& ALMEIDA, P. A. M. de - Elementos de avaliação do "risco gravídico". Rev. Saúde públ., S. Paulo, 6: 57-78, 1972.

\section{REFERENCIAS BIBLIOGRAFICAS}

1. BEARD, R. W. \& ROBERTS, A. P. Assymptomatic bacteriuria during pregnancy. Brit. med. Bull., 24: 44-8, 1968.

2. BERTOLA, R. P. et al. - Fatores del risco gravídico, Obst. Ginec. lat. amer., 29: 107-12, 1971.

3. Davies, A. M. et al. - Toxemia of pregnancy in J'erusalem 1. Epidemiological studies of a total community. Israel $\mathrm{J}$. Med. Sci., 6: 253-66, 1970.

4. EFFER, S. B. - Management of hightrisk pregnancy: report of a combined obstetrical and neo-natal intensive care unit. Canad. med. Ass. J., 101: 55-63, 1969.

5. GOLD, E. M. \& STONE, M. L. - Total maternal and infant care: a realistic appraisal. Amer. J. publ. Hlth., 58 . 1219-29, 1968.

6. INFORME sobre el Progresso de la Investigacion Interamericana de Mortalidad en la Niñ'ez. Washington, D.C., Organizacion Panamericana de La Salud, 1970. [Apresentado a la 9.a reunião del Comité Assessor de Investigación Médica de la OPS/OMS, 1970].

7. ORGANIZATION MONDIALE DE LA SANTE - Organisation et administration des services de protection maternelle et infantil. Genève, 1969. (Sér. rapp. téchn. n.० 428).

8. SLOWINSKY, E. Y. - Screening for bacteriuria in pregnancy. Postgrad. Med., 43: 124-8, Jan. 1968.

9. SZKLO, M. - A saúde materna como prioridade na assistência médica: enfoque epidemiologico. Rio de Janeiro, F'ac. Ciências Médicas, 1971 [mimeografado].

10. YUNES, J. - Diagnóstico da situação da saúde pública no município de são Paulo. Rev. Hosp. Clin. Fac. Med. S. Paulo, 25: 83-9, 1970.

Recebido para publicação em 13-12-1971

Aprovado para publicą̧āo em 7-1-1972 